\title{
Potential of the To Ma To HAKA in the Last Stand of Wildlife Protection and the Failure of the State
}

\author{
${ }^{*}$ Clifford Tafangenyasha \\ Department of Geography and Environmental Science, University of Zimbabwe, Africa
}

Submission: April 29, 2017; Published: May 04, 2017

*Corresponding author: Clifford Tafangenyasha, Department of Geography and Environmental Science, University of Zimbabwe, ZIMPARKS, PO Box CY 1204, Causeway, Harare, Zimbabwe, Africa, Email: cliffordtafa@gmail.com

\begin{abstract}
Wildlife protection is a futile exercise that should inevitably result in species doom and extinctions if there are no turnaround motivational strategies. Guns, drones, handcuffs and imprisonment represent hard approaches in wildlife conservation which may have not worked with rhino, elephant and tiger protection. Smart approaches endeavour to dwell on the primary of motivational demonstrations at instruction issuing parades and environmental awareness and education campaigns. Adapting the To ma To HAKA Rugby technique is simple enough to replace the status quo at instruction parades. The HAKA should be translated as a medium for captivating the game guards and instil apprehension in the counter culture participants. Audience in the participation should simply enjoy the motif and permanently embed the doctrines of wildlife conservation and even encourage self-reporting. The adapted HAKA can be monitored using established protocols in more recent literature. The HAKA provides a useful template that can be adapted to suit sovereignty and public acceptance. HAKA represents a remedy to the failure of the state in wildlife protection.
\end{abstract}

Keywords: HAKA; Rugby motivation; Biodiversity conservation; Conservation motivational paradigm; Wildlife loss control; Wildlife smart techniques

\section{Introduction}

The degradation of the natural resources exacerbated by economic downturn and rapid population growth in areas adjacent to protected areas Scoones [1]. The failure to implement sustainable natural resources management strategies at local and community levels leads to resource depletion as well as fragmentation of natural habitats and the erosion of genetic diversity of wild and cultivated plants Chibisa [2]. There is a strong need to review the methods used in environmental awareness and education. The harvesting of natural resources by a few illegal collectors has been contextualized by Gareth Hardin [3] in the "Tragedy of the Commons" "that which is common to all is prone to abuse" given their open access nature, wildlife resources are bound to suffer over-exploitation. The underlying reason of the tragedy is best summed up in the conservative dictum "everybody's good is nobody's property" Hardin [3]. To avoid the "tragedy of the commons" additional, comprehensive and proactive environmental awareness methods should be introduced in the short term to long term. The improvements in environmental education may largely depend on directed instructions, self-learning toolkits group directed learning toolkits and information from new technologies.
Science has a long tradition of improving concepts and techniques from its promising branches to improve on other disciplines. American Physicist Richard Feynman (19181988) improved on the theory and mathematics of quantum electrodynamics using borrowed techniques from other disciplines of physics. Similarly, Biologists Shannon and Weaver efficiently developed principles of calculations of plant diversity indices from wave technology. In the attempt to arrive at the theory of everything physicist Albert Einstein (1879-1955) used various conjectures from various sources. In a similar vein HAKA a child brain of New Zealand most successful All Blacks Rugby team has potential to reverse the losses in rhino, elephant, tiger and lion among a few species.

The To- Ma- To- HAKA is a pre- cursor to successful game development in Rugby that raises the bar in emotions, captivating zeal, personal and team ego in sport development to stratospheric levels in competitive sport. HAKA invokes a high degree of patriotism and discipline in law enforcement and should be a game changer in the protection of all things. The paper presents a problem of great importance in securing the protection of wildlife. What alternative paradigms are available 
to comprehensively protect wildlife? The study exploits gaps in the understanding of holistic wildlife protection. Should the status quo be left on the sidelines when biodiversity is increasingly coming under intense illegal extraction pressure? This study provides the most overlooked aspects of stimulating environment of organised law enforcement and awareness. Tafangenyasha et al. [4] suggested that wildlife protection can be guaranteed in the foreseeable future if novel stimulating environments are found. The findings corroborate the findings by earlier workers Scoones [1], Kahn [5].

From wildlife briefing parade participants should walk away with real expectations of apprehending counterculture nuisances. Africa, like much of the biodiversity rich third world lacks in motivational drive and ownership of team spirit to win the antipoaching game. Tafangenyasha et al. [4] suggest that African governments and their national parks are engaged in a sophisticated arms race with poachers, a game that can simply be won on stage/theatre using simple captivating motivational demonstrations of the spirit of the mind. The HAKA pre-game tactics has a key result of drastically reducing wildlife losses through postures that embellishes wildlife policing. The HAKA postures reciprocal interest, martial warning signals and simplicity across wide sections of stakeholders. Efficient wildlife protection measures require regular updates in bush craft and indoctrination protocols. This way HAKA can be a carrier of environmental messages in the outback's of Africa and perhaps beyond.

The present tactics of indoctrinating wildlife policing start with the usual parade address system that has not been adapted to adequately suit wildlife protection. The game of invigorating staff should start at the parade and be taken downstream in road shows and pro-active law enforcement strategies that are simply interesting to the lay men. The HAKA tactic is repeatable as it is musical, artistic and conductible at environmental awareness and education campaigns. A de-novo approach in providing a new moral high ground is envisaged. The study strengthens the view that soft approaches in law enforcement are still limitless and inexhaustible.

\section{Materials and Methods}

Credits are given to Getty images in Wikipedia (Figures 1-6) for a close up demonstration of HAKA that originated as a traditional dance among the Maori in New Zealand.

\section{HAKA Indoctrination Techniques}

Chants, hand and leg gyrations are carefully ordered and manipulated in sequence and power to indicate ferocious tactics that have the full potential to annihilate counter culture groups or opponents in a contest (Figures 1-6). In a rugby contest HAKA may be construed to have fluttering tactics that fail to defeat opponents but because practice and rehearsals are perfect and proficiently carried out the end result may often be a hard earned trophy. Team members are supposed to chant and gyrate in unison in manners that frighten opponents. Chants carry invincible songs, strategies and visions and missions of a team. Chants empower team members. This technique developed and refined by All Blacks Rugby team represent an honest approach by humankind at reaching harmony in a naturally challenging environment where foes want to dominate.

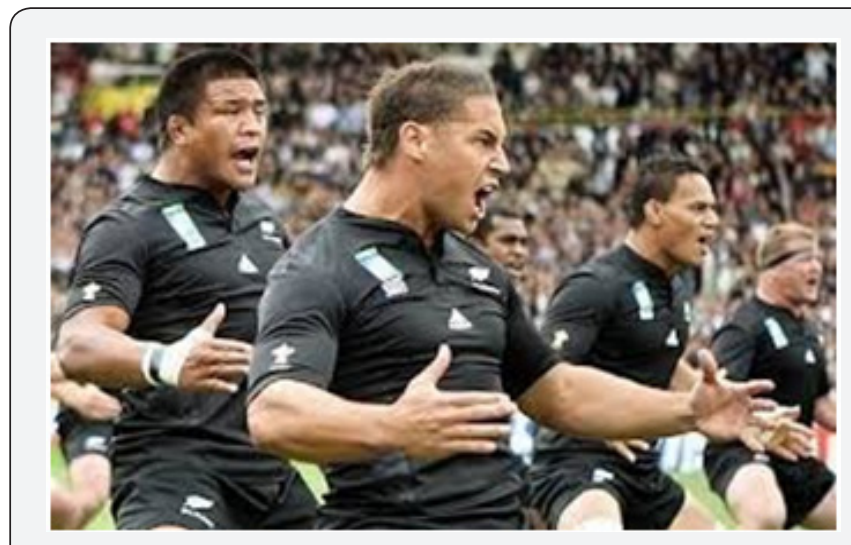

Figure 1: Gyrations first level in Haka formidable rugby team display.

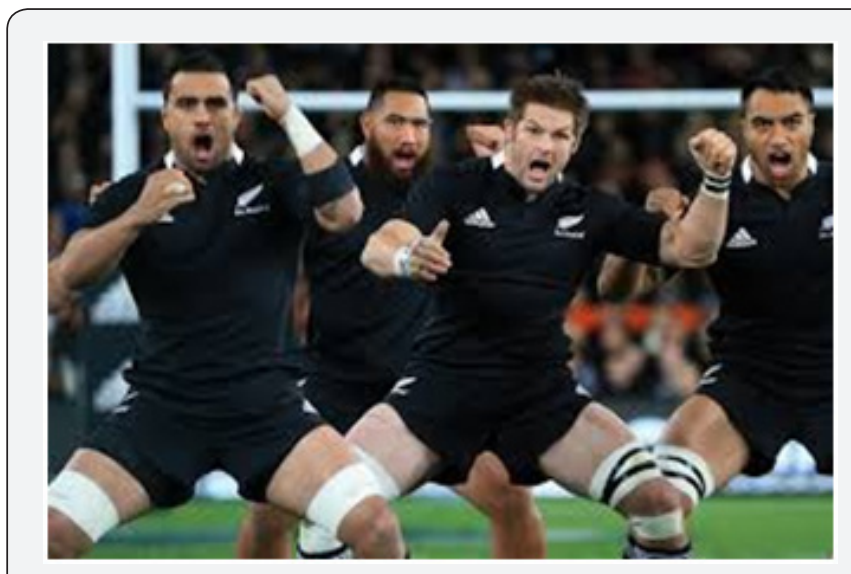

Figure 2: Chant and gyrations in complementary rugby action.

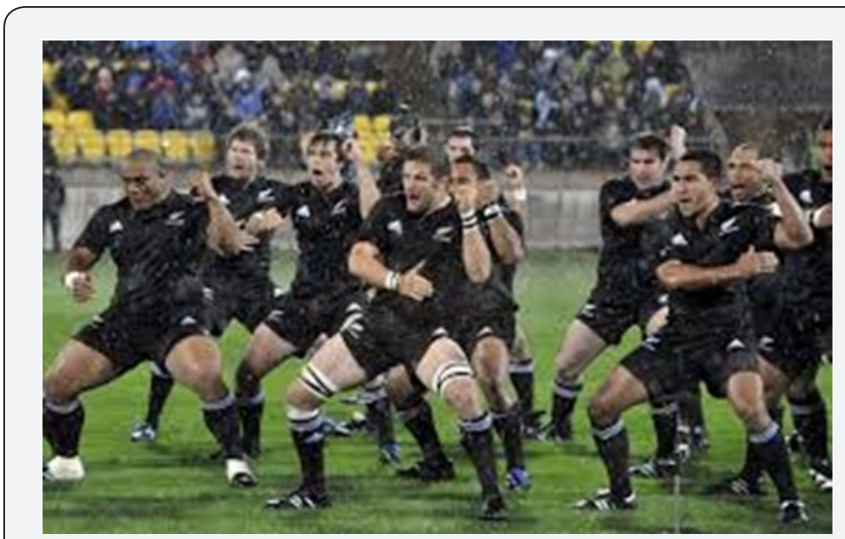

Figure 3: Muscular chant and gyrations in rugby team winning philosophy. 


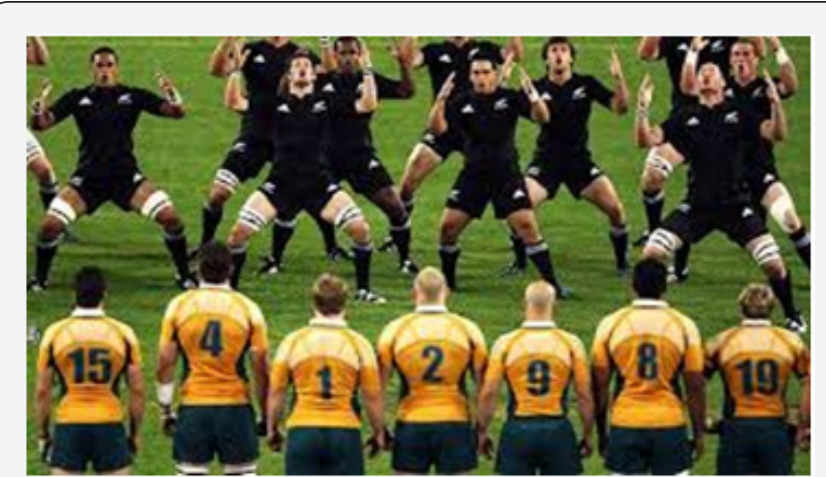

Figure 4: Formidable haka display overtures in front of rugby opponents.

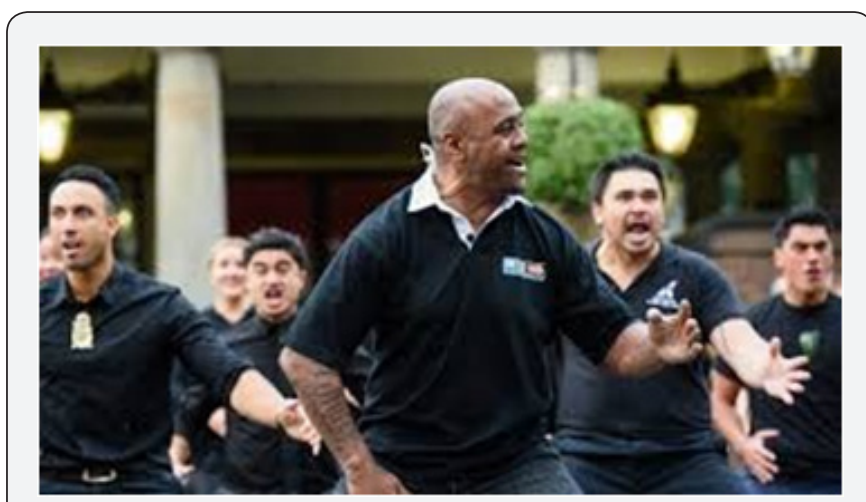

Figure 5: Joyous relief haka follow a game over celebration.

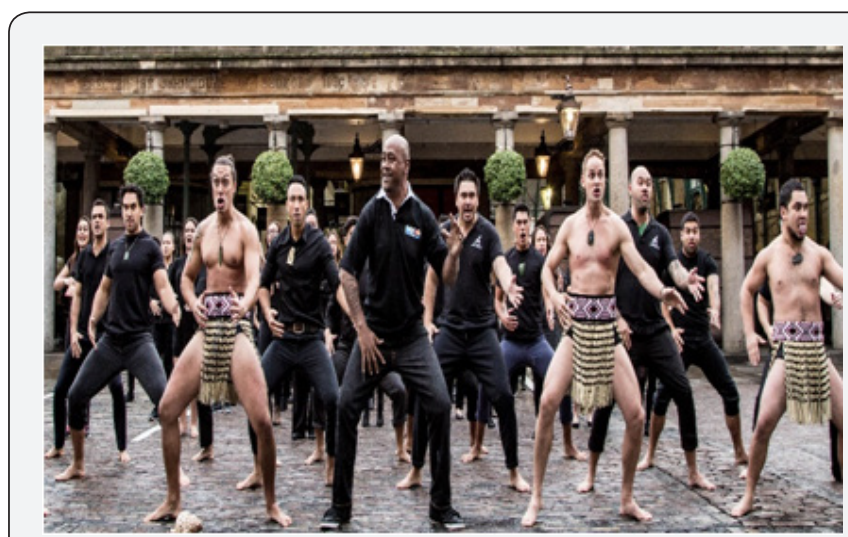

Figure 6: Celestial Haka thanks giving follow a rugby game win.

\section{Results and Discussion}

HAKA adoption by rugby teams around the world has been pivotal in raising the bar in rugby game inspiration. Rugby teams associated with HAKA have produced sterling results. Who said sound wildlife protection measures should not borrow from the catchment of ideas that produce desirable results in stimulation of team members? Tafangenyasha et al. [4] suggested parameters for testing effectiveness and efficiency of novel techniques in wildlife conservation.

\section{Adoption by International Sporting Team}

HAKA has long been adopted as a team rejuvenating game prior to a rugby contest in New Zealand (Figures 1-6). The All Blacks Rugby Team and scrumhalf Jonah Lomu (1975-2015) captivating demonstrations have inspired and given hope to rugby players and followers across the globe. According to anecdotes the HAKA allows practitioners to maintain allegiance to team spirit, discipline and highest levels of fitness and agility. The strategy addresses the here and now and the next now in law enforcement personnel readiness. HAKA has been accepted and tried in Australia, South Africa Springboks, Micronesia Pacific, Europe and Japan among others.

\section{Potential of HAKA Deployment in Wildlife Protection and Measurement of Monitoring Efficiencies}

It is imperative that HAKA should bring a game on in wildlife protection with conservation counter culture groups. Wildlife protection should thrive on new innovative principles that engage law enforcement personnel and disengage counter culture participants in conservation. Traditional inefficient loss control procedures are not cast in concrete since each generation has to meet current needs in reducing loss of all things using robust war games and plays. HAKA should gain acceptance in commercial security companies through creation of formidable teams. HAKA should instil readiness and capacity to spring and jump at counter cultures promoting loss of things. Loss control departments may be receptive to new concepts and techniques and HAKA is the alternative paradigm antidote to counterculture against loss of all things. Tafangenyasha et al. [4] have highlighted the failure of the state in protecting all things and the need to invoke all measures to protect all things in the environment. Tafangenyasha et al. [4] are implicit in the need for the state to do more to reduce loss of things.

\section{Problems with HAKA Deployment Across Law Enforcement}

Conceivably, HAKA may be labelled a foreign preparedness doctrine and technique that may not be suitable to the prevailing parade status quo that has proven disenabling as a protocol in loss control measures.

\section{Future Adaptation and Development of HAKA}

HAKA provides an interesting learning curve from teams overhauling psychological readiness protocols. Mediocre readiness performances in world rugby sporting tournaments has not been tolerated at competitive sport tournaments. HAKA may be conceived as a corrective rejuvenating mechanism/ factor in law enforcement and tends to supplant less captivating traditional wildlife protection parades. The paper provides a stimulating point for further research. Winner take all motif is at the core of HAKA indoctrination. 


\section{Acknowledgement}

The author is indebted to the 2015 DSTV BBC Television relay of rugby scrumhalf Jonah Lomu's (1975-2015) New Zealand All Blacks Rugby partial funeral coverage proceedings where the captivating HAKA demo was highly inspirational. Grateful thanks are extended to anonymous reviewers for comments that have substantially improved the original manuscript.

\section{References}

1. Henry Bernstein (2010) Zimbabwe's land reform: myths and realities- By Ian Scoones, Nelson Marongwe, Blasio Mavedzenge, Jacob Mahenehene, Felix Murimbarimba and Chrispen Sukume. Journal of Agrarian Change 12(1): 170-173.
2. Chibisa P, Ruzive A, Mandipa CT (2005) The 2000-2004 Fast track land reform Programme and Biodiversity issues in the middle Save Conservancy. Clarion University of Pennsylvania, Clarion, USA.

3. Hardin G (1968) Tragedy of the commons. Science 162(3859): 12431248.

4. Tafangenyasha Clifford, Moyo Gilbert, Ngorima Patmore, Stephen Sengwa (2015) The environmental officer, environmental awareness and the trouble with CAMPFIRE in lessons on environmental management in a specific park in Zimbabwe. Journal of Agricultural Extension and Rural Development 3(11): 326-337.

5. Alan Mandell, Xenia Coulter (2010) Critical pedagogy, eco-literacy and planetary crisis: the ecopedagogy movement, by Richard Kahn. Critical Policy studies 5(4): 186.

\section{Your next submission with Juniper Publishers} will reach you the below assets

- Quality Editorial service

- Swift Peer Review

- Reprints availability

- E-prints Service

- Manuscript Podcast for convenient understanding

- Global attainment for your research

- Manuscript accessibility in different formats

( Pdf, E-pub, Full Text, Audio)

- Unceasing customer service

Track the below URL for one-step submission https://juniperpublishers.com/online-submission.php 